\title{
Biofeedback-Based Connected Mental Health Interventions for Anxiety: Systematic Literature Review
}

Mahra Alneyadi, BSc; Nidal Drissi, MSc; Mariam Almeqbaali, BSc; Sofia Ouhbi, PhD

Department of Computer Science \& Software Engineering, College of Information Technology, Al Ain, Abu Dhabi, United Arab Emirates

Corresponding Author:

Sofia Ouhbi, $\mathrm{PhD}$

Department of Computer Science \& Software Engineering

College of Information Technology

United Arab Emirates University

Al Ain, Abu Dhabi, 15551

United Arab Emirates

Phone: 9713713 ext 5568

Email: sofia.ouhbi@uaeu.ac.ae

\begin{abstract}
Background: Connected mental health, which refers to the use of technology for mental health care and technology-based therapeutic solutions, has become an established field of research. Biofeedback is one of the approaches used in connected mental health solutions, which is mainly based on the analysis of physiological indicators for the assessment and management of the psychological state. Biofeedback is recommended by many therapists and has been used for conditions including depression, insomnia, and anxiety. Anxiety is associated with several physiological symptoms, including muscle tension and breathing issues, which makes the inclusion of biofeedback useful for anxiety detection and management.
\end{abstract}

Objective: The aim of this study was to identify interventions using biofeedback as a part of their process for anxiety management and investigate their perceived effectiveness.

Methods: A systematic literature review of publications presenting empirically evaluated biofeedback-based interventions for anxiety was conducted. The systematic literature review was based on publications retrieved from IEEE Digital Library, PubMed, ScienceDirect, and Scopus. A preliminary selection of papers was identified, examined, and filtered to include only relevant publications. Studies in the final selection were classified and analyzed to extract the modalities of use of biofeedback in the identified interventions, the types of physiological data that were collected and analyzed and the sensors used to collect them. Processes and outcomes of the empirical evaluations were also extracted.

Results: After final selection, 13 publications presenting different interventions were investigated. The interventions addressed either primarily anxiety disorders or anxiety associated with health issues such as migraine, Parkinson disease, and rheumatology. Solutions combined biofeedback with other techniques including virtual reality, music therapy, games, and relaxation practices and used different sensors including cardiovascular belts, wrist sensors, or stretch sensors to collect physiological data such as heart rate, respiration indicators, and movement information. The interventions targeted different cohorts including children, students, and patients. Overall, outcomes from the empirical evaluations yielded positive results and emphasized the effectiveness of connected mental health solutions using biofeedback for anxiety; however, certain unfavorable outcomes, such as interventions not having an effect on anxiety and patients' preferring traditional therapy, were reported in studies addressing patients with specific physical health issues.

Conclusions: The use of biofeedback in connected mental health interventions for the treatment and management of anxiety allows better screening and understanding of both psychological and physiological patient information, as well as of the association between the two. The inclusion of biofeedback could improve the outcome of interventions and boost their effectiveness; however, when used with patients suffering from certain physical health issues, suitability investigations are needed.

(JMIR Mhealth Uhealth 2021;9(4):e26038) doi: 10.2196/26038

\section{KEYWORDS}

anxiety; biofeedback; systematic literature review; mental health; eHealth; mHealth; connected health; digital health 


\section{Introduction}

\section{Background}

Anxiety is the brain's way of reacting to stress and alerting to possible danger, which makes it an expected feeling in a person's daily life, as it can be triggered by normal daily scenarios $[1,2]$. However, the persistence of this feeling might be an indicator that the person is suffering from an anxiety disorder. Anxiety disorder is an umbrella term that comprises various mental disorders characterized by excessive anxiety, tension, and fear that interfere with the person's daily life and interrupt the normal execution of daily tasks and activities [2]. There are 5 main types of anxiety disorders [3]: generalized anxiety disorder, obsessive compulsive disorder, panic disorder, posttraumatic stress disorder, and phobia. Most anxiety disorders affect women 2 times more than they affect men [3]. The causes of anxiety disorders are not clear and differ from one person to another based on many factors. Anxiety can be triggered by difficult life experiences, surrounding environment, and health behavior or can be caused by physical factors, such as overactive brain areas involved in emotions and behavior, genetics, and brain chemistry $[4,5]$. In addition to psychological symptoms, anxiety is also associated with many physiological symptoms including muscle tension, heartbeat issues, breathing issues, sweating, dry mouth, and headaches $[1,3,5]$.

Connected mental health is the subfield of connected health that refers to the use of information and communication technologies for mental health care and includes all related areas such as mobile mental health, digital mental health, tele-mental health and e-mental health [6]. Connected mental health now plays a crucial role in the health care sector and contributes to improving the delivery of mental health care by providing novel, affordable, and easy-to-access solutions [6,7]. Technology has been included in mental health care in several forms including the exploitation of sensors for mental states' detection and management [8], mobile apps for mental health care [9], and websites $[10,11]$. Use of technology has also facilitated access to many therapeutic solutions for anxiety disorders and mental health generally [7]. Examples include virtual reality (VR), computer- and internet-based cognitive behavioral therapy, and biofeedback [7]. VR is a 3D environment that can be either similar to or different from the real world. It allows the patients to interact with a specific environment based on the psychological issue and feared stimuli [12]. Computer-based cognitive behavioral therapy and self-rated mental health help evaluate the patient's mental health via apps or websites by analyzing the user's answers to certain mental state assessment questions [13]. Patients can also use chatbots and online therapy services to communicate with mental health professionals and obtain a diagnosis [13,14]. Biofeedback-based mental health interventions aim to identify the patient's mental state by monitoring body activities [15].

Biofeedback for mental health is based on measuring physiological changes associated with psychological states [16] to help monitor the body functions that are affected by the psychological reactions. Biofeedback-based interventions use and monitor different physiological factors, including heart rate, galvanic skin response (also known as electrodermal response), and respiration measurements. The main aim of biofeedback training is to provide patients with awareness and insight on their physiological changes, helping them better control those changes, and consequently, better control their mental state. Biofeedback has been shown to be one of the useful ways to help reduce the symptoms of anxiety disorders [17]. The physiological manifestations of anxiety make biofeedback useful in anxiety detection and treatment solutions.

Biofeedback could be useful for several mental health issues, such as stress, anxiety, hypertension, and depression [18]. Moreover, advances in technology have allowed biofeedback to become affordable, cost-effective, and easily used by practitioners as well as users [18]. The aim of this paper was to investigate the use of biofeedback in connected mental health solutions for anxiety disorders by conducting a systematic literature review. We investigated modalities of biofeedback use by identifying treatment approaches combined with it, types of sensors used in the interventions, and the physiological data collected and analyzed. In addition, we reviewed empirical evidence on the effectiveness of biofeedback-based interventions for anxiety from intervention outcomes.

\section{Related Work}

Biofeedback is becoming one of the complementary and alternative medicine forms recommended by many doctors and therapists [16]. This section presents examples of literature addressing the adoption of biofeedback in treatment solutions for anxiety disorders and other mental issues.

Biofeedback in combination with psychotherapy was used for military medical providers suffering from anxiety, depression, and insomnia [19]. Psychotherapy helped reduce symptoms of anxiety and depression but could not improve insomnia issues. Yet when combined with biofeedback, the treatment was able to improve the sleep of the military medical providers [19].

A portable biofeedback device was integrated into clinical practice for patients with anxiety who were receiving cognitive behavioral therapy-based treatment [20]. Patients reported higher satisfaction with biofeedback-based treatment compared to that reported for other relaxation techniques such as meditation, yoga, and unassisted breathing. It was reported that biofeedback could be a promising treatment adjunct for disorders of autonomic arousal and could be easily integrated into treatment [20].

An exploratory review [21] investigated the efficacy of treating anxiety disorders in children and adolescents using biofeedback, cognitive behavioral therapy, and mindfulness combined with technological tools and programs, including serious games, web-based tools, apps, and internet-based tools. It reported that connected health interventions were found to be effective for anxiety management, as many studies reported they were as effective as traditional treatments.

Moreover, other studies [22-24] discussed the effectiveness of biofeedback in serious games for emotion regulation and mental health, generally. They reported that there was promising evidence for integrating biofeedback in serious games for managing anxiety [22-24]. Biofeedback has been reported as a 
successful approach to practice emotion regulation and was also found to improve performance on decision-making tasks in serious games [22]. Moreover, examples of existing biofeedback-based games have shown positive results for reducing depression and anxiety [24].

Figure 1. Review process.

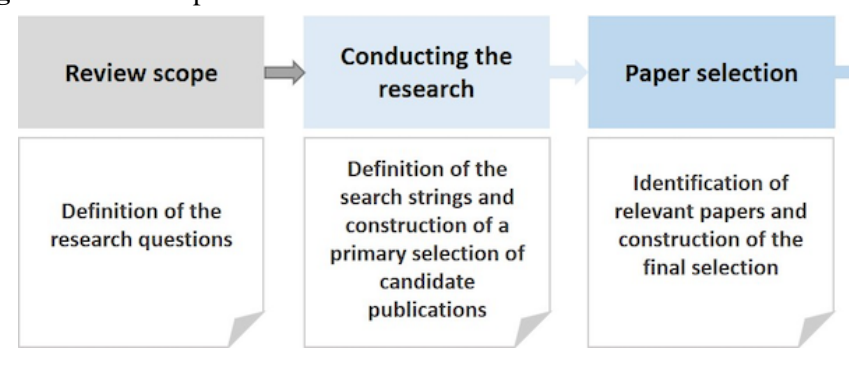

\section{Research Questions}

We attempted to answer the following 2 research questions: (1) What are the biofeedback-based connected mental health interventions for anxiety available in the literature? (2) How effective are biofeedback-based connected mental health solutions in treating anxiety? The first aims to identify the different treatment approaches that could be combined with biofeedback for the management of anxiety, as well as the different types of sensors and physiological information that could be used in biofeedback-based interventions. The second

\section{Methods}

\section{Overview}

We aimed to investigate the modalities of use of biofeedback in connected mental health solutions for anxiety disorders, as well as investigate the empirical evidence on such solutions. This study follows the quality reporting guidelines set out by PRISMA (Preferred Reporting Items for Systematic Reviews and Meta-analysis [25]). Figure 1 summarizes the review process.

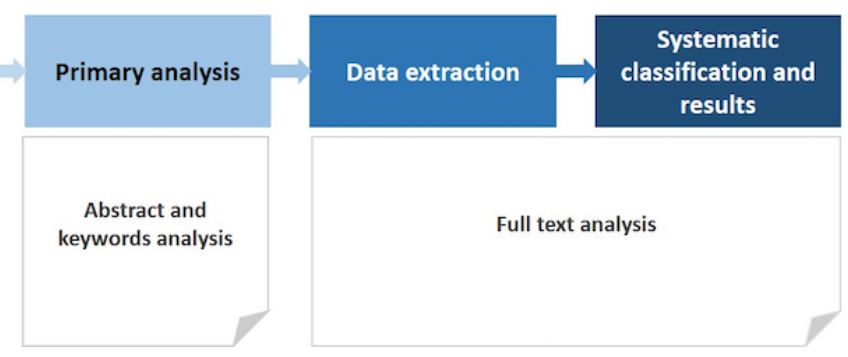

aims to identify patients' interaction with the biofeedback treatments in connected mental health solutions and how beneficial it is to their case and level of anxiety.

\section{Research Method}

The search for candidate papers was conducted in IEEE Digital Library, PubMed, ScienceDirect, and Scopus using the search strings presented in Table 1. The search strings included relevant terms and were formulated to identify a wide selection of candidate publications.

Table 1. Search strings.

\begin{tabular}{|c|c|}
\hline ID & Search string \\
\hline 1 & 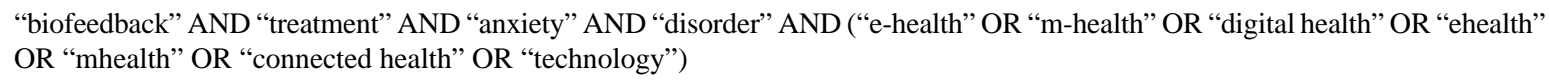 \\
\hline 2 & (“computer" OR “mobile”) AND “biofeedback” AND “anxiety” AND “disorder” AND “games" \\
\hline
\end{tabular}

\section{Paper Selection}

After the primary selection of candidate papers by applying the search strings to the digital libraries, duplicates were removed and the candidate publications were first analyzed by inspecting the titles then filtered based on a set of eligibility criteria to construct a final selection of relevant studies (Figure 2). Papers were selected based on the following inclusion criteria: studies that (1) addressed treating anxiety using biofeedback, and (2) combined information and communication technologies and biofeedback to treat anxiety. Exclusion criteria were any of the following: (1) publications that were not original research papers (eg, index or abstract); (2) studies that presented biofeedback as a treatment for general mental health or other issues, such as depression, but not anxiety; (3) studies that did not combine information and communication technologies and biofeedback to treat anxiety; or (4) studies that were not empirically evaluated (eg, reviews). 
Figure 2. Selection process.

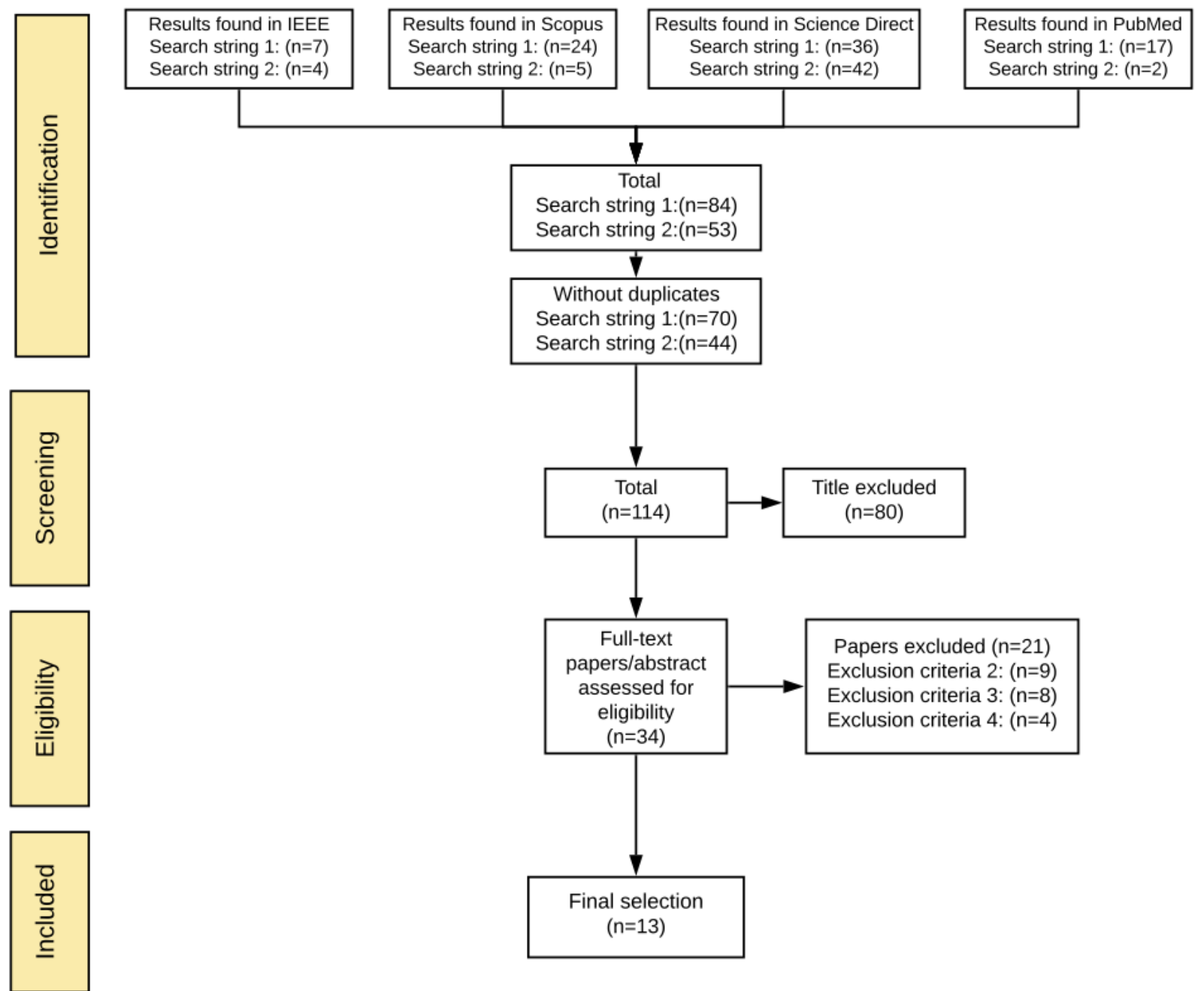

\section{Data Collection}

Studies in the final selection were analyzed to extract relevant information. A data extraction form with predefined fields was developed in a spreadsheet (Microsoft Excel 2016). Data were extracted and categorized. While extracting data, we focused mainly on answering the research questions by identifying treatment approaches combined with biofeedback for anxiety management, the cohort groups addressed by the interventions, types of physiological data analyzed in the interventions, sensors used to collect the data, the processes of the empirical evaluations conducted on the interventions, and the outcome of empirical evaluations. Studies were then classified, mainly by grouping the interventions by cohort group and treatment approach.

\section{Synthesis}

The synthesis method used in this study consisted of reading and analyzing selected studies, categorizing the data extracted from selected studies, and classifying the studies by enumerating the number of interventions for each data category. It should be noted that interventions including more than one treatment approach, more than one type of physiological data, or more than one type of sensor were counted in each category. The results are presented in figures and tables, because visualization of the results facilitated their analysis, and as a narrative summary describing the interventions and principal findings.

\section{Results}

\section{Search Results}

A total of 114 candidate publications were identified; however, only 13 studies met the eligibility criteria and were included in the final selection (Figure 2); 10 were published from 2011 to 2020, 2 were published in 2009, and 1 was published in 2002 . The selected studies targeted people from different cohort groups: 8 of the interventions targeted mainly anxiety, while the rest addressed health issues associated with anxiety. In interventions that were identified, biofeedback was combined with different treatment techniques. Information on the publications, including targeted health issues and targeted cohort groups, are presented in Table 2, and information on processes and outcomes of the empirical evaluations are presented in Multimedia Appendix 1. 
Table 2. Final selection.

\begin{tabular}{clll}
\hline Age category/reference & Year of publication & Cohort group & Condition \\
\hline Adults & & & \\
{$[26]$} & 2020 & Patients with Parkinson disease & Anxiety \\
{$[27]$} & 2019 & Patients with rheumatic diseases & Pain and anxiety \\
{$[28]$} & 2018 & $\begin{array}{l}\text { Patients with drug-resistant temporal lobe } \\
\text { epilepsy seizures }\end{array}$ & Associated anxiety, stress, and depression \\
[29] & 2014 & Teachers and nurses & Psychological stress including anxiety \\
{$[30]$} & 2009 & Patients with generalized anxiety disorder & Anxiety \\
Young adults & & & \\
{$[31]$} & 2018 & Youth in residential care & Anxiety \\
{$[32]$} & 2016 & College students & Anxiety \\
{$[33]$} & 2009 & University students & Anxiety related to their studies \\
Children and adolescents & & & \\
{$[34]$} & 2017 & Children and adolescents with autism & Anxiety and performance \\
{$[35]$} & 2016 & Children & Risk of anxiety \\
{$[36]$} & 2015 & Pediatric patients & Pain and anxiety \\
{$[24]$} & 2011 & Children and adolescents & Anxiety \\
{$[37]$} & 2002 & Children & Migraine and anxiety \\
\hline
\end{tabular}

Identified treatment techniques included biofeedback with VR, targeted by interventions. Figure 4 presents the association games, and relaxation practices used with different cohort groups between treatment techniques and physiological data types. including children and adolescents, young adults, and patients (Figure 3). Children and adolescents were the age group most Data related to heart activity and skin response were used the most.

Figure 3. Bubble chart associating the treatment techniques with the target cohorts.

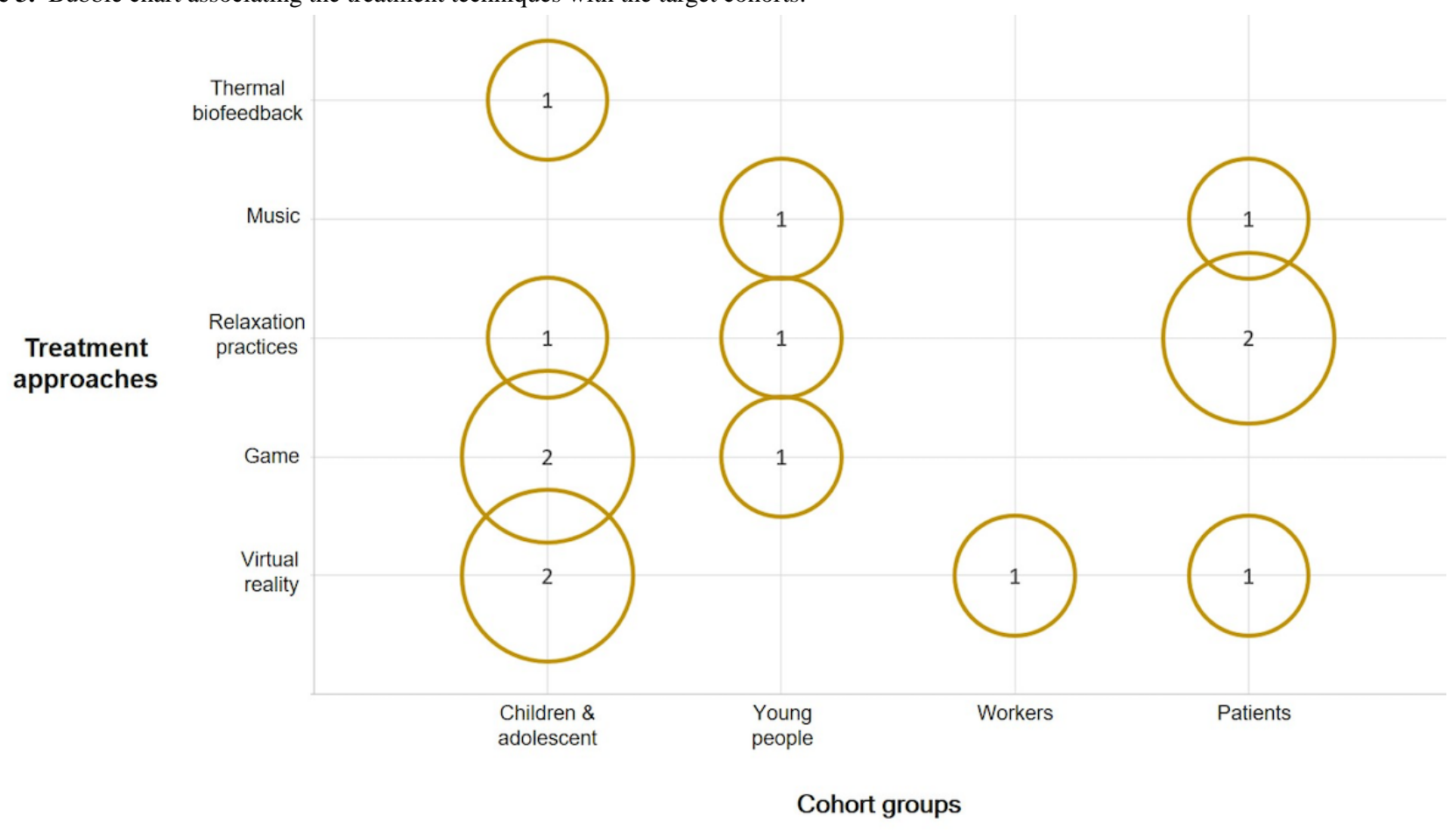


Figure 4. Bubble chart associating the treatment techniques with physiological indicators analyzed in the papers.

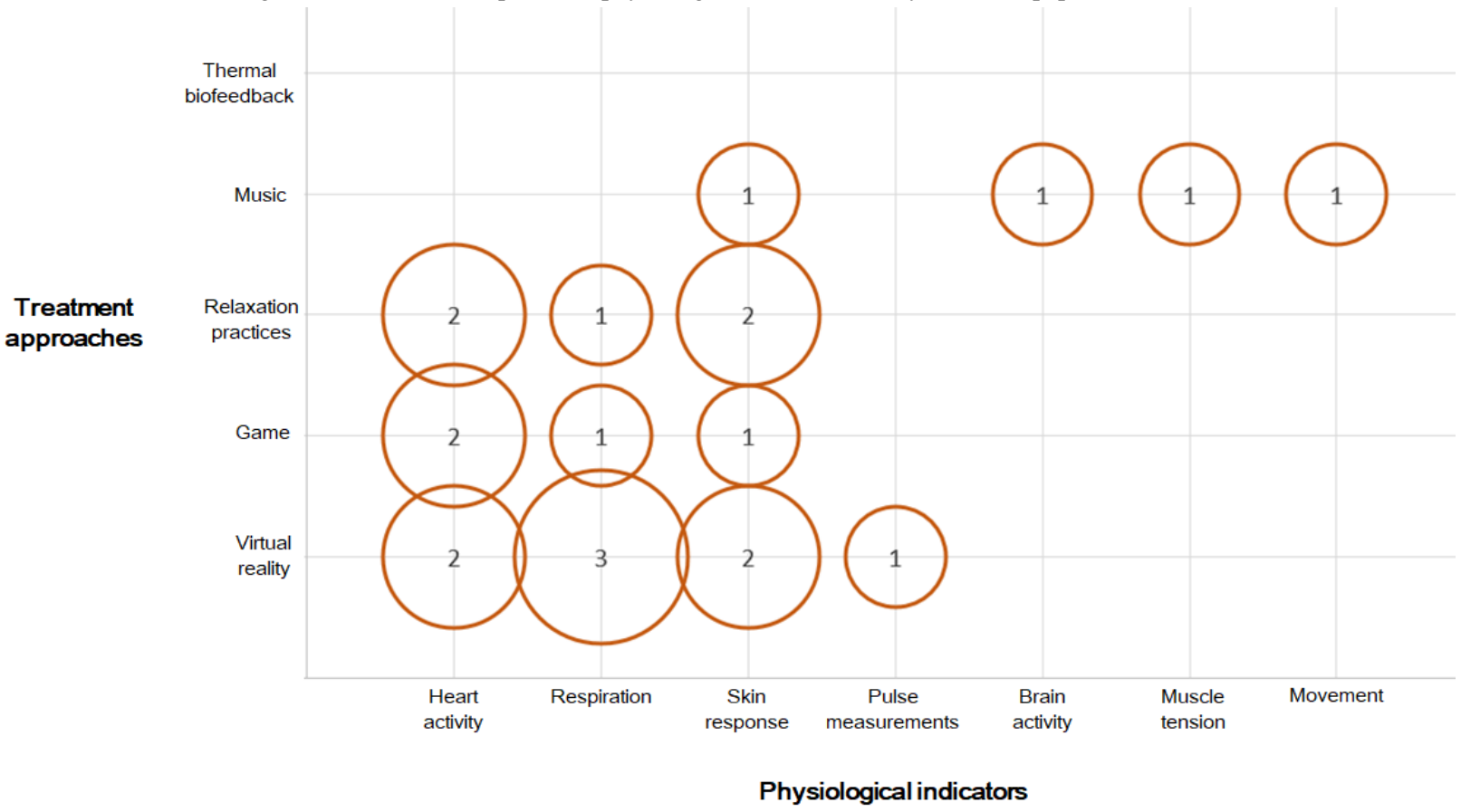

\section{Interventions for Adults}

Of the 13 studies, 5 presented solutions for adults [26-30], 4 of which addressed patients [26-28,30]. Two of the solutions for patients were based on VR [27,30]. One was a VR-based biofeedback and guided meditation system for the management of pain and anxiety in patients with rheumatic disease [27] consisting of modules with and without respiratory biofeedback, monitored using a microphone. The user, when interacting with the VR environment, is instructed to breathe along to an oscillating pacer. Patients who used the intervention preferred the guided meditation module that did not include biofeedback over the module with biofeedback [27]. The other VR-based solution [30] was for the treatment of generalized anxiety disorder using VR and mobile phones, in which the user explored a virtual island by following a therapist-recorded narrative that included relaxation exercises. The user was also connected to biosensors that record physiological parameters including skin conductance, heart rate, and respiration. Some of the virtual experience elements were directly modified by the real-time heart rate variability of the user. Including biofeedback in the VR-based mobile intervention resulted in a higher decrease of anxiety than the VR-based mobile intervention without biofeedback [30].

Music therapy was also used with biofeedback; one intervention [26] consisted of an Ambulosono system for patients with Parkinson disease. The system is based on a method of musical gait training that rewards desirable gait behaviors with music play. The system comprised wireless headphones and a combination of a music player and a wearable sensor (iOS gyroscope and accelerometer) worn above the knee of the user to collect movement and step information. During gait biofeedback training, music is played when the user achieves a set stride length. Even though the data used in this intervention were not related to psychological status, the intervention had a secondary impact on patients' levels of depression and anxiety [26].

A biofeedback system based on skin conductance used for the management of nonpharmacological epilepsy and associated anxiety, depression, and stress was proposed in [28]. The system presents the users with movies to trigger certain emotions that users were required to control [28]. While the users watched the films, skin conductance was measured and recorded using electrodes on the index and middle finger of the left hand of the participant. The study reported that skin conductance response was not related to changes in anxiety levels, which is contradictory to the findings of other studies in which skin conductance was used as an indicator of anxiety [38,39]. Yet this contradiction might be specific to the group targeted by the intervention. Even though the intervention reported a decrease in patients' anxiety and depression, it was suggested that this decrease reflects a nonspecific or a placebo effect of using the intervention [28].

For adult workers, particularly teachers and nurses [29], an intervention consisting of virtual scenarios with real-time monitoring was used for the management of the psychological state. The system put the user in virtual scenarios of stressful experiences and natural scenarios to learn certain relaxation techniques while the user was connected to cardiovascular belt and wrist biosensors to collect heart rate and heart rate variability. Data collected by the sensors were assessed by a decision support system that provided users with a real-time graphical representation of their current stress level. Some of the elements of the virtual experience were driven by the emotional status of the patient, measured by the biosensors. In this intervention, the combination of VR with biofeedback showed significantly better results than those of VR interventions without biofeedback or traditional treatments. The combination of VR and biofeedback showed better results in 
reducing anxiety when compared to traditional cognitive behavioral therapy treatment [29].

\section{Interventions for Young People}

Of the 13 studies, 3 addressed mainly young people [31-33]. One of the interventions was a biofeedback video game called Dojo for anxiety and externalizing problems for young people in residential care [31]. The game promoted emotion regulation by providing tutorials on cognitive behavioral therapy-based relaxation techniques such as deep breathing, progressive muscle relaxation, positive thinking, and guided imagery. The game also included mini games that trigger different emotions such as fear, frustration, and anger and require the users to regulate their emotions using the techniques. User heart rate was monitored while playing the game through a biofeedback hardware and was displayed on the screen. Users were required to control their physiological reaction to succeed in the game, thus encouraging them to regulate their emotions [31].

Two interventions $[32,33]$ targeted college students. One was based on music therapy and biofeedback treatment for anxiety [32]. The intervention provided the user with a relaxing music experience and judged the effect by measuring dynamic changes including skin resistance, as well as electroencephalography and electromyography indicators [32]. Another intervention provided biofeedback training to help university students overcome anxiety related to their studies [33]. The intervention is based on using a stress sweeper biofeedback device for the physiological measurements. Collected physiological indicators included heart rate and respiration. The biofeedback device helped guide participants while they practiced techniques to reduce anxiety related to their studies [33].

\section{Interventions for Children and Adolescents}

Of the 13 studies, 5 presented solutions for children and adolescents [24,34-37]: 3 studies presented interventions based on games [24,35,36], including the programs Freeze-Framer and Journey to the Wild Divine, to reduce anxiety and depression. The programs were biofeedback-assisted relaxation training games that included cognitive behavioral therapy. The interventions used 2 to 3 electrodes to record momentary changes in heart rate variability and skin conductance levels. An example of a biofeedback relaxation activity offered by the programs is one in which users built a bridge - the user was required to relax to continue the construction of the bridge. As user breathing slows and tension decreases, the bridge is built; if the user experiences frustration or anxiety, the bridge disappears. After a continuous period of relaxation, the bridge is finished and the user can cross it [24]. Journey to the Wild Divine [36] collects heart rate variability and skin temperature of the users via sensors attached to the users' fingers. The program contains 15 levels, and completing one level requires meeting certain relaxation standards. Quick completion of a level is an indication of the ability of the patient to quickly regulate their physiological response and relax [36].

A VR biofeedback breathing game called DEEP [35] situates users in an underwater fantasy world, where they can move freely. The game is not based on levels or goals; rather, it provides personal breathing and meditation support by promoting diaphragmatic breathing through biofeedback. The game collects breathing data using a stretch sensor. A microcontroller interprets the sensor readings and sends data to the game, where it is used to change the user experience and manipulate the game elements. Slow and deep breathing allows players to move forward in the game, thus promoting diaphragmatic breathing. The intervention showed promising results; it was reported to decrease anxiety in a timely manner [35].

VR was also used in an anxiety-sensitive and performance-sensitive adaptive system for children with autism [34]. The system was composed of different modules including VR-based social communication, real-time physiological data acquisition, intelligent anxiety predictor, and strategy generator modules. The system captured photoplethysmography, electrodermal activity, and skin temperature signals to use as anxiety predictors. The system's purpose was to identify and quantify the user's anxiety level from real-time biomarkers, along with performance metrics during social communication simulations. The system adapts, progressing through different levels of tasks, based on the anxiety and performance metrics [34].

A system providing thermal biofeedback treatment to children suffering from migraine [37] included two types of thermal treatments, hand-warming biofeedback and hand-cooling biofeedback, to help the children deal with their migraine symptoms and anxiety. The treatments had different effects on migraines, yet did not affect anxiety levels [37].

\section{Empirical Evaluations}

All 13 studies presented processes and outcomes of empirical evaluations. The empirical evaluations, in general, followed similar protocols: they included participants based on sets of eligibility criteria and divided participants into intervention and control groups who were wait-listed or received traditional treatment. Overall, the empirical evaluations yielded positive results. However, unfavorable outcomes were reported in some studies (Multimedia Appendix 1).

\section{Discussion}

\section{Main Findings}

Interventions identified in this review used biofeedback with different treatment techniques, different sensors and physiological data, and for different purposes; however, all the interventions followed the same logic (Figure 5). The process begins with physiological data collection via sensors attached to the user. Physiological data are then processed and analyzed to generate a type of feedback from the system. In the interventions identified in this review, 2 main types of feedback were reported. Based on the readings of the physiological data the interventions either modified the user interface and experience or offered a visual presentation of the physiological changes. 
Figure 5. Layer diagram for a biofeedback-based system. EEG: electroencephalography; EMG: electromyography; GSR: galvanic skin response; HR: heart rate; PPG: photoplethysmography.

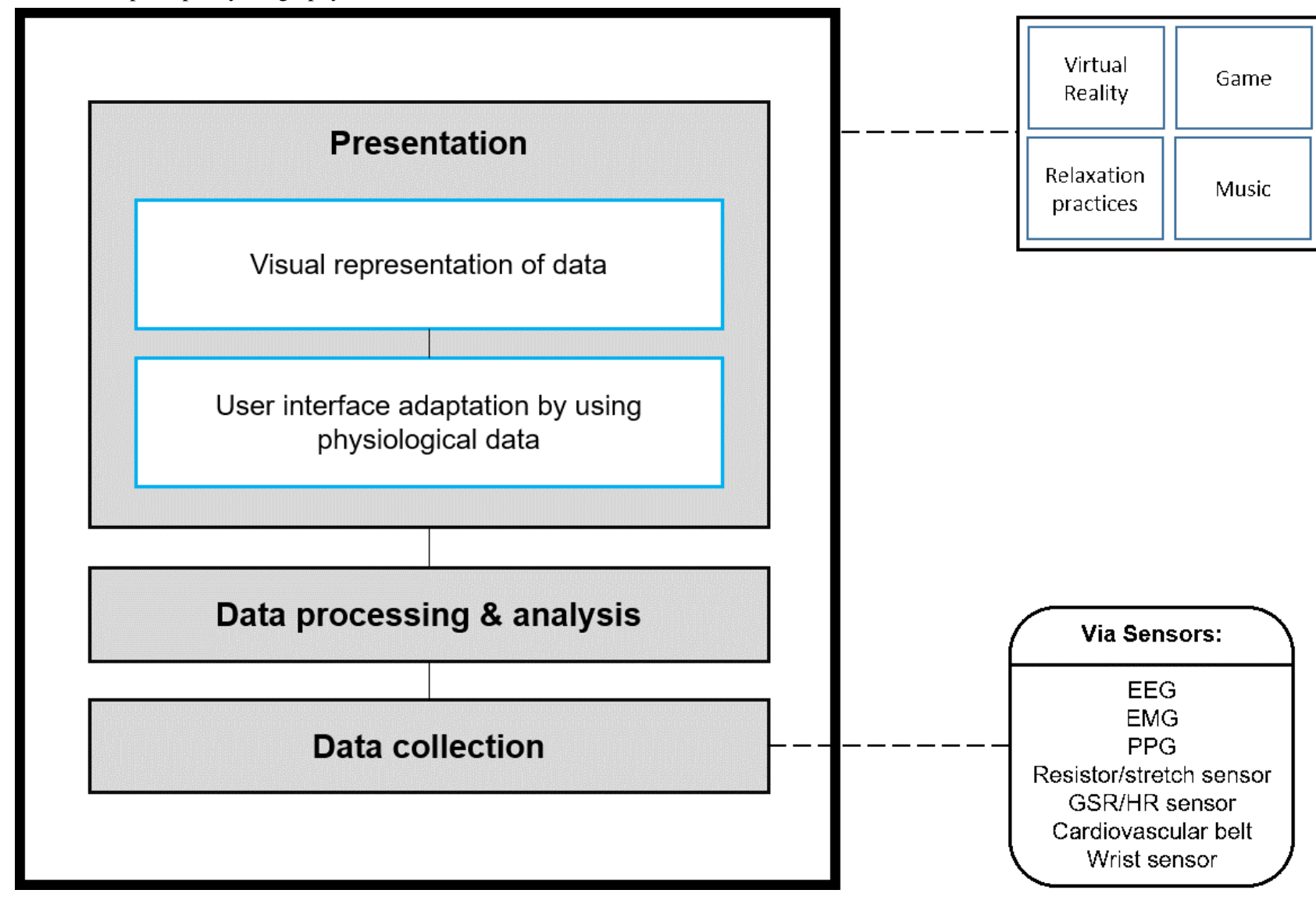

\section{Biofeedback With VR and Games}

Biofeedback was mostly found to be combined with VR and was found to increase the efficacy of such interventions [29,30]. The VR concept emerged in the 1980s and is based on transforming any real situation into a virtual experience. VR is based on the basic elements of generating images, presenting sensory information, and updating the displayed images based on the users' position and orientation [40]. VR has the potential to create rich sensory experiences [41] and has been used for the management of different mental issues, such as the treatment of anxiety [42]. VR has been widely used for anxiety, by exposing patients to virtual situations triggering anxiety and teaching them how to deal with such situations. VR-based treatments have been used for different anxiety issues [43], including phobia management [44], mainly for the delivery of exposure therapy. VR facilitates exposure therapy exercises because they can be conducted in the therapist's office rather than in real-world phobic situations [44]. VR exposure has also been found to be effective for panic disorder [45] and in helping veterans with posttraumatic stress disorder [46].

Having issues interacting with the world is at the core of many psychological issues, including anxiety. VR could be a useful approach to face that issue, as it helps to simulate real-life experiences for the patients. Examples include helping manage phobia issues, which are characterized by intense fear and anxiety when interacting with certain elements, and posttraumatic stress disorder, in which patients have flashbacks of traumatizing experiences [42]. VR and biofeedback were also used with children [35], suggesting that it can be a children-friendly treatment. VR was used with children with multiple disabilities to familiarize them with the use of the wheelchair [47]. Moreover, VR has also been adopted into different types of games for purposes such as interactive entertainment, interactive training, and education [48]. The combination of VR with games has also been used in different medical settings as well, including medical training [49] and rehabilitation treatments [50].

Games have been coupled with biofeedback for mental health. Games for health can be classified as serious games, which mainly refers to games that do not focus on enjoyment, entertainment, and fun as their main purpose [51] but rather on elements such as education, training, and health improvement [52]. Quality games have been shown to influence behavior [53] and enhance concentration [54], as well as to facilitate learning and information retention [55,56]. Blending biofeedback with games has shown promising results. A computer biofeedback game based on animated gut imagery was used with people with irritable bowel syndrome and helped patients decrease their stress as well as mitigate symptoms related to their physical disorder [57]. Biofeedback-based games have also been used for physical issues management, for example, in balance training for people affected by chronic hemiplegic stroke, which showed positive results and was reported to be a feasible adjunct to conventional therapy [58].

Interventions including games mainly targeted the young generation [24,31] and have been shown to be effective. Young 
people are heavy users of technology, in general, and are the most familiar with gaming technologies, as millions of adolescents and young adults play video games and are the primary users of games $[59,60]$. Heavy use of technology and familiarity with games makes the young generation a suitable group for the use of game-based mental health care interventions. When introduced to VR interventions and games, biofeedback helped enhance the virtual and gaming experiences and encouraged user engagement, in addition to providing insight on user physiological and psychological states to help with the management of health issues. However, it must be noted that for such interventions to be helpful, user needs, experience, and preferences should be at the heart of their design $[23,42]$.

\section{Biofeedback With Relaxation Practices and Music}

Relaxation techniques and practices include somatic methods such as progressive relaxation, breathing, stretching, and physical exercises, as well as cognitive approaches including imagery, meditation, goal-directed visualization, and self-awareness [61]. These methods have been shown to be effective in mitigating anxiety and stress [61,62]. Biofeedback was coupled with such practices in some interventions $[33,36]$ to inform users about the changes in their physiological measurements to help them better understand the association between their psychological and physiological indicators. Biofeedback inclusion was effective in the reduction of anxiety in these interventions $[33,36]$.

Representing results with graphs, diagrams, animations, or other in order to deliver information for better understanding is used in education and is viewed as an effective teaching tool [63]. The same approach was used with patients to educate them about their health, which resulted in the patients being more satisfied, becoming more knowledgeable, and gaining understanding about their health issues [64]. In the case of anxiety, helping patients better understand and follow their case, the physiological changes associated with their mental issue, and treatment modalities can help them be more aware of the effect of anxiety on their bodies and help them be more accepting and trusting of the treatment applied, which might even influence the outcome of the treatment. Relaxation techniques were also used for pediatric pain management [33]. Relaxation techniques may be effective complementary therapies to pharmacologic techniques for pediatric pain, which can help reduce or even eliminate the amount of medication needed to treat the pain [65]. Relaxation approaches have also been used to manage other types of pain, including labor pain during childbirth [66], perioperative pain [67], and chronic pain [68].

Music with biofeedback was also among the relaxation techniques that showed positive results [32]. Music therapy has been shown to regulate both the physical and the mental health by affecting both the physiology and psychology of the person. Music can be combined with and included in different mental health management approaches and relaxation techniques [69] and can be used as a relaxation method on its own, as it was reported to be as effective as the progressive muscle relaxation method [70]. Because preferred or accepted types of music can be different in each community, when including music in psychological treatments, cultural consideration might be necessary [69].

Relaxation practices and music-based techniques have been widely adopted in technology-based interventions for anxiety, mainly in mobile apps [14]. Relaxation practices and music influence not only the psychology but also the physiology of our bodies. The inclusion of biofeedback could help improve mental care interventions based on those techniques. Biofeedback provides insight on physiological changes, which helps patients both assess and manage their psychological state.

\section{Biofeedback for Anxiety Associated With Other Health Issues}

Anxiety was found to be common among patients of many physical disorders including patients with cancer [71] and people suffering from chronic obstructive pulmonary disease [72]. Anxiety is also common when undergoing medical procedures, such as magnetic resonance imaging [73]. Therefore, some interventions addressed symptoms of specific health issues and the anxiety associated with their prevalence [27,28,34]. Those interventions included solutions based on combining biofeedback with VR, which, in certain cases, showed unfavorable results [27]. This might be due to VR not being suitable for patients with health issues such as migraine, headache, seizure disorder, and vestibular abnormalities [43]. In addition, anxiety caused by the prevalence of specific health issues is generally impacted by the progress of the health issue itself, which might indicate that, in the interventions addressing other health issues, anxiety levels were impacted as a result of the change in the user's health but not as a direct effect of the intervention on anxiety specifically [26,37].

\section{Implications}

This review may be of interest to researchers, mental health interventions' developers, and practitioners interested in the use of biofeedback in mental health management as it presents descriptions and analysis of 13 examples of biofeedback-based interventions for anxiety and different treatment approaches that could be combined with biofeedback, including VR, games, and music therapy. We also presented physiological indicators that could be exploited in biofeedback-based interventions and analyzed for anxiety management including heart rate measurements, respiration, and movement, which could be collected using different sensors including wrist sensors, cardiovascular belts, electroencephalography, and electromyography. The review showed different cohorts that could benefit from biofeedback-based interventions including children, patients, and workers. The interventions have generally yielded positive results in improving anxiety.

Use of biofeedback allowed better screening, understanding, and control of physiological factors during anxiety management interventions, improving outcomes and effectiveness; however, a need for additional investigation for certain health issues was highlighted.

It must be noted that this review might have some limitations: (1) the inclusion of other terms in the search string might result in additional publications and (2) searching Google Scholar might have resulted other relevant studies. 
For future work, we intend to use the findings of this review to collaborate with mental health care professionals to create a biofeedback-based mobile app for the management of anxiety for young adults in United Arab Emirates.

\section{Acknowledgments}

This work is part of the Abu Dhabi Young Investigator Award 2019 (AYIA19-001) awarded by the Abu Dhabi Research and Development Authority and the Startup project (31T131) funded by the United Arab Emirates University.

\section{Conflicts of Interest}

None declared.

\section{Multimedia Appendix 1}

Empirical evaluations.

[DOCX File, 28 KB-Multimedia Appendix 1]

\section{References}

1. Anxiety disorders. National Institute of Mental Health. 2018. URL: https://www.nimh.nih.gov/health/topics/anxiety-disorders/ index.shtml [accessed 2021-01-04]

2. Anxiety disorders. WebMD. 2020. URL: https://www.webmd.com/anxiety-panic/guide/anxiety-disorders\\#1 [accessed 2021-01-04]

3. Nutt DJ. Overview of diagnosis and drug treatments of anxiety disorders. CNS Spectr 2005 Jan 07;10(1):49-56. [doi: 10.1017/s1092852900009901] [Medline: 15618947 ]

4. Martin EI, Ressler KJ, Binder E, Nemeroff CB. The neurobiology of anxiety disorders: brain imaging, genetics, and psychoneuroendocrinology. Psychiatr Clin North Am 2009 Sep;32(3):549-575 [FREE Full text] [doi: 10.1016/j.psc.2009.05.004] [Medline: 19716990]

5. Generalised anxiety disorder in adults. National Health Service. 2018. URL: https://www.nhs.uk/conditions/ generalised-anxiety-disorder/ [accessed 2021-01-04]

6. Drissi N, Ouhbi S, Janati Idrissi MA, Fernandez-Luque L, Ghogho M. Connected mental health: systematic mapping study. J Med Internet Res 2020 Aug 28;22(8):e19950 [FREE Full text] [doi: 10.2196/19950] [Medline: 32857055]

7. Przeworski A, Newman MG. Efficacy and utility of computer-assisted cognitive behavioural therapy for anxiety disorders. Clin Psychol 2006 Aug 20;10(2):43-53. [doi: 10.1080/13284200500378779]

8. Drissi N, Ouhbi S, García-Berná J, Idrissi M, Ghogho M. Sensor-based solutions for mental health care: a systematic literature review. In: Proceedings of the 13th International Joint Conference on Biomedical Engineering Systems and Technologies. 2020 Presented at: 13th International Conference on Health Informatics; February 24-26; Valletta, Malta p. 593-600. [doi: 10.5220/0009100805930600]

9. Drissi N, Ouhbi S, Idtissi M, Ghogho M. Gamification-based apps for PTSD: an analysis of functionality and characteristics. Abu Dhabi, United Arab Emirates; 2019 Presented at: 16th ACS/IEEE International Conference on Computer Systems and Applications; November 3-7; Abu Dhabi, United Arab Emirates. [doi: 10.1109/aiccsa47632.2019.9035325]

10. Zermatten A, Khazaal Y, Coquard O, Chatton A, Bondolfi G. Quality of web-based information on depression. Depress Anxiety 2010 Sep;27(9):852-858. [doi: 10.1002/da.20665] [Medline: 20099271]

11. Barnes C, Harvey R, Wilde A, Hadzi-Pavlovic D, Wilhelm K, Mitchell PB. Review of the quality of information on bipolar disorder on the internet. Aust N Z J Psychiatry 2009 Jan;43(10):934-945. [doi: 10.1080/00048670903179137]

12. Maples-Keller JL, Bunnell BE, Kim S, Rothbaum BO. The use of virtual reality technology in the treatment of anxiety and other psychiatric disorders. Harv Rev Psychiatry 2017;25(3):103-113 [FREE Full text] [doi: 10.1097/HRP.0000000000000138] [Medline: 28475502]

13. Ebert DD, Zarski A, Christensen H, Stikkelbroek Y, Cuijpers P, Berking M, et al. Internet and computer-based cognitive behavioral therapy for anxiety and depression in youth: a meta-analysis of randomized controlled outcome trials. PLoS One 2015;10(3):e0119895 [FREE Full text] [doi: 10.1371/journal.pone.0119895] [Medline: 25786025]

14. Drissi N, Ouhbi S, Janati Idrissi MA, Ghogho M. An analysis on self-management and treatment-related functionality and characteristics of highly rated anxiety apps. Int J Med Inform 2020 Sep 30;141:104243 [FREE Full text] [doi: 10.1016/j.ijmedinf.2020.104243] [Medline: 32768994]

15. Ratanasiripong P, Ratanasiripong N, Kathalae D. Biofeedback intervention for stress and anxiety among nursing students: a randomized controlled trial. ISRN Nurs 2012;2012:827972 [FREE Full text] [doi: 10.5402/2012/827972] [Medline: 22811932]

16. Frank DL, Khorshid L, Kiffer JF, Moravec CS, McKee MG. Biofeedback in medicine: who, when, why and how? Ment Health Fam Med 2010 Jun;7(2):85-91 [FREE Full text] [Medline: 22477926] 
17. Ratanasiripong P, Kaewboonchoo O, Ratanasiripong N, Hanklang S, Chumchai P. Biofeedback intervention for stress, anxiety, and depression among graduate students in public health nursing. Nurs Res Pract 2015;2015:160746 [FREE Full text] [doi: 10.1155/2015/160746] [Medline: 25954515]

18. Ratanasiripong P, Sverduk K, Prince J, Hayashino D. Biofeedback and counseling for stress and anxiety among college students. J Coll Stud Dev 2012;53(5):742-749. [doi: 10.1353/csd.2012.0070]

19. McLay RN, Spira JL. Use of a portable biofeedback device to improve insomnia in a combat zone, a case report. Appl Psychophysiol Biofeedback 2009 Dec 5;34(4):319-321. [doi: 10.1007/s10484-009-9104-3] [Medline: 19655243]

20. Reiner R. Integrating a portable biofeedback device into clinical practice for patients with anxiety disorders: results of a pilot study. Appl Psychophysiol Biofeedback 2008 Mar;33(1):55-61. [doi: 10.1007/s10484-007-9046-6] [Medline: 18286369]

21. Tozzi F, Nicolaidou I, Galani A, Antoniades A. eHealth interventions for anxiety management targeting young children and adolescents: exploratory review. JMIR Pediatr Parent 2018 May 10;1(1):e5 [FREE Full text] [doi:

10.2196/pediatrics.7248] [Medline: $\underline{31518330]}$

22. Jerčić P, Sundstedt V. Practicing emotion-regulation through biofeedback on the decision-making performance in the context of serious games: a systematic review. Entertain Comput 2019 Mar;29:75-86. [doi: 10.1016/j.entcom.2019.01.001]

23. Fleming TM, Bavin L, Stasiak K, Hermansson-Webb E, Merry SN, Cheek C, et al. Serious games and gamification for mental health: current status and promising directions. Front Psychiatry 2016;7:215. [doi: 10.3389/fpsyt.2016.00215] [Medline: 28119636]

24. Knox M, Lentini J, Cummings T, McGrady A, Whearty K, Sancrant L. Game-based biofeedback for paediatric anxiety and depression. Ment Health Fam Med 2011 Sep;8(3):195-203 [FREE Full text] [Medline: 22942901]

25. Liberati A, Altman DG, Tetzlaff J, Mulrow C, Gøtzsche PC, Ioannidis JPA, et al. The PRISMA statement for reporting systematic reviews and meta-analyses of studies that evaluate health care interventions: explanation and elaboration. J Clin Epidemiol 2009 Oct;62(10):e1-34 [FREE Full text] [doi: 10.1016/j.jclinepi.2009.06.006] [Medline: 19631507]

26. Burt J, Ravid EN, Bradford S, Fisher NJ, Zeng Y, Chomiak T, et al. The effects of music-contingent gait training on cognition and mood in parkinson disease: a feasibility study. Neurorehabil Neural Repair 2020 Jan;34(1):82-92. [doi: 10.1177/1545968319893303] [Medline: 31878824]

27. Venuturupalli RS, Chu T, Vicari M, Kumar A, Fortune N, Spielberg B. Virtual reality-based biofeedback and guided meditation in rheumatology: a pilot study. ACR Open Rheumatol 2019 Dec;1(10):667-675 [FREE Full text] [doi: 10.1002/acr2.11092] [Medline: 31872189]

28. Kotwas I, McGonigal A, Khalfa S, Bastien-Toniazzo M, Bartolomei F, Micoulaud-Franchi J. A case-control study of skin conductance biofeedback on seizure frequency and emotion regulation in drug-resistant temporal lobe epilepsy. Int $\mathbf{J}$ Psychophysiol 2018 Jan;123:103-110. [doi: 10.1016/j.ijpsycho.2017.10.005] [Medline: 29042154]

29. Gaggioli A, Pallavicini F, Morganti L, Serino S, Scaratti C, Briguglio M, et al. Experiential virtual scenarios with real-time monitoring (interreality) for the management of psychological stress: a block randomized controlled trial. J Med Internet Res 2014 Jul 08;16(7):e167 [FREE Full text] [doi: 10.2196/jmir.3235] [Medline: 25004803]

30. Pallavicini F, Algeri D, Repetto C, Gorini A, Riva G. Biofeedback, virtual reality and mobile phones in the treatment of Generalized Anxiety Disorder (GAD): a phase-2 controlled clinical trial. J Cyber Ther Rehabil 2009;2(4):315-327 [FREE Full text]

31. Schuurmans AAT, Nijhof KS, Engels RCME, Granic I. Using a videogame intervention to reduce anxiety and externalizing problems among youths in residential care: an initial randomized controlled trial. J Psychopathol Behav Assess 2018;40(2):344-354 [FREE Full text] [doi: 10.1007/s10862-017-9638-2] [Medline: 29937625]

32. Li F, Xiong Y. Application of music therapy combined with computer biofeedback in the treatment of anxiety disorders. In: Proceedings of the 8th International Conference on Information Technology in Medicine and Education. Fuzhou, China; 2016 Presented at: 8th International Conference on Information Technology in Medicine and Education; December 23-25; Fuzhou, China p. 90-93. [doi: 10.1109/itme.2016.0029]

33. Vitasari P, Wahab M, Othman A, Awang M. The effectiveness of biofeedback training among university students. Malaysia; 2009 Presented at: IEEE Student Conference on Research and Development (SCOReD); October 15-17; Serdang, Malaysia p. 551-554. [doi: 10.1109/scored.2009.5442939]

34. Kuriakose S, Lahiri U. Design of a physiology-sensitive vr-based social communication platform for children with autism. IEEE Trans Neural Syst Rehabil Eng 2017 Aug;25(8):1180-1191. [doi: 10.1109/tnsre.2016.2613879]

35. van Rooij M, Lobel A, Harris O, Smit N, Granic I. DEEP: a biofeedback virtual reality game for children at-risk for anxiety. San Jose, California, USA; 2016 Presented at: CHI Conference on Human Factors in Computing Systems; May 7-12; San Jose, California, USA. [doi: 10.1145/2851581.2892452]

36. McKenna K, Gallagher KAS, Forbes PW, Ibeziako P. Ready, set, relax: biofeedback-assisted relaxation training (BART) in a pediatric psychiatry consultation service. Psychosomatics 2015;56(4):381-389. [doi: 10.1016/j.psym.2014.06.003] [Medline: 25556570]

37. Scharff L, Marcus DA, Masek BJ. A controlled study of minimal-contact thermal biofeedback treatment in children with migraine. J Pediatr Psychol 2002 Mar;27(2):109-119. [doi: 10.1093/jpepsy/27.2.109] [Medline: 11821495]

38. Krusemark EA, Li W. Enhanced olfactory sensory perception of threat in anxiety: an event-related fMRI study. Chemosens Percept 2012 Mar 01;5(1):37-45 [FREE Full text] [doi: 10.1007/s12078-011-9111-7] [Medline: 22866182] 
39. Ihmig FR, Neurohr-Parakenings F, Schäfer SK, Lass-Hennemann J, Michael T. On-line anxiety level detection from biosignals: machine learning based on a randomized controlled trial with spider-fearful individuals. PLoS One 2020;15(6):e0231517 [FREE Full text] [doi: 10.1371/journal.pone.0231517] [Medline: $\underline{32574167]}$

40. Slater M, Sanchez-Vives MV. Enhancing our lives with immersive virtual reality. Front Robot AI 2016 Dec 19;3:74. [doi: $10.3389 /$ frobt.2016.00074]

41. Burdea G, Coiffet P. Virtual reality technology. Presence (Camb) 2003 Dec 01;12(6):663-664. [doi: 10.1162/105474603322955950]

42. Freeman D, Reeve S, Robinson A, Ehlers A, Clark D, Spanlang B, et al. Virtual reality in the assessment, understanding, and treatment of mental health disorders. Psychol Med 2017 Oct;47(14):2393-2400 [FREE Full text] [doi: 10.1017/S003329171700040X] [Medline: 28325167]

43. Gorini A, Riva G. Virtual reality in anxiety disorders: the past and the future. Expert Rev Neurother 2008 Feb 09;8(2):215-233. [doi: 10.1586/14737175.8.2.215] [Medline: 18271709]

44. Powers MB, Emmelkamp PMG. Virtual reality exposure therapy for anxiety disorders: a meta-analysis. J Anxiety Disord 2008;22(3):561-569. [doi: 10.1016/j.janxdis.2007.04.006] [Medline: 17544252]

45. Botella C, García-Palacios A, Villa H, Baños RM, Quero S, Alcañiz M, et al. Virtual reality exposure in the treatment of panic disorder and agoraphobia: a controlled study. Clin Psychol Psychother 2007 May;14(3):164-175. [doi: 10.1002/cpp.524]

46. Rothbaum BO, Hodges LF, Ready D, Graap K, Alarcon RD. Virtual reality exposure therapy for Vietnam veterans with posttraumatic stress disorder. J Clin Psychiatry 2001 Aug 15;62(8):617-622. [doi: 10.4088/JCP.v62n0808]

47. Rodriguez N. Identifying accessibility conditions for children with multiple disabilities: a virtual reality wheelchair simulator. 2018 Presented at: IEEE International Symposium on Mixed and Augmented Reality Adjunct (ISMAR-Adjunct); October 16-18; Munich, Germany. [doi: 10.1109/ismar-adjunct.2018.00107]

48. Zyda M. From visual simulation to virtual reality to games. Computer 2005 Sep;38(9):25-32. [doi: 10.1109/mc.2005.297]

49. Schild J, Misztal S, Roth B, Flock L, Luiz T, Lerner D, et al. Applying multiuser virtual reality to collaborative medical training. In: Proceeding of the IEEE Conference on Virtual Reality and 3D User Interfaces. Reutlingen; 2018 Presented at: IEEE Conference on Virtual Reality and 3D User Interfaces; March 18-22; Tuebingen/Reutlingen, Germany p. $775-776$. [doi: $10.1109 /$ vr.2018.8446160]

50. Laver KE, Lange B, George S, Deutsch JE, Saposnik G, Crotty M. Virtual reality for stroke rehabilitation. Cochrane Database Syst Rev 2017 Nov 20;11:CD008349 [FREE Full text] [doi: 10.1002/14651858.CD008349.pub4] [Medline: 29156493]

51. Michael D, Chen S. Serious Games: Games That Educate, Train and Inform. Boston, Massachussetts: Thomson Course Technology; 2006.

52. Stapleton A. Serious games: serious opportunities. 2004 Presented at: Australian Game Developers Conference, Academic Summit; December 2; Melbourne, Australia p. 2.

53. Read JL, Shortell SM. Interactive games to promote behavior change in prevention and treatment. JAMA 2011 Apr 27;305(16):1704-1705. [doi: 10.1001/jama.2011.408] [Medline: 21447802]

54. Connolly TM, Boyle EA, MacArthur E, Hainey T, Boyle JM. A systematic literature review of empirical evidence on computer games and serious games. Comput Educ 2012 Sep;59(2):661-686. [doi: 10.1016/j.compedu.2012.03.004]

55. Andrews A. Serious games for psychological health education. 2011 Presented at: International Conference on Virtual and Mixed Reality; July 9-14; Orlando, Florida p. 3-10. [doi: 10.1007/978-3-642-22024-1 1]

56. Dondlinger M. Educational video game design: a review of the literature. J Appl Educ Technol 2007;4(1):21-31 [FREE Full text]

57. Leahy A, Clayman C, Mason I, Lloyd G, Epstein O. Computerised biofeedback games: a new method for teaching stress management and its use in irritable bowel syndrome. J R Coll Physicians Lond 1998;32(6):552-556. [Medline: 9881312]

58. Hung J, Yu M, Chang K, Lee H, Hsieh Y, Chen P. Feasibility of using Tetrax biofeedback video games for balance training in patients with chronic hemiplegic stroke. PM R 2016 Oct;8(10):962-970. [doi: 10.1016/j.pmrj.2016.02.009] [Medline: 26968609]

59. Gough C. Distribution of video gamers worldwide in 2017, by age group and gender. Statista. 2017. URL: https://www. statista.com/statistics/722259/world-gamers-by-age-and-gender/ [accessed 2021-01-04]

60. Gough C. Share of active mobile gamers worldwide in 2020, by age group. Statista. 2020. URL: https://www.statista.com/ statistics/748089/number-mobile-gamers-world-platform/ [accessed 2021-01-04]

61. Payne R, Donaghy M. Payne's Handbook of Relaxation Techniques 4th Edition. Amsterdam: Elsevier Health Sciences; 2010.

62. Eppley KR, Abrams AI, Shear J. Differential effects of relaxation techniques on trait anxiety: a meta-analysis. J Clin Psychol 1989 Nov;45(6):957-974. [doi: 10.1002/1097-4679(198911)45:6<957::aid-jclp2270450622>3.0.co;2-q]

63. Vavra KL, Janjic-Watrich V, Loerke K, Phillips LM, Norris SP, Macnab J. Visualization in science education. Alta Sci Educ J 2011;41(1):22-30.

64. Enzenhofer M, Bludau H, Komm N, Wild B, Mueller K, Herzog W, et al. Improvement of the educational process by computer-based visualization of procedures: randomized controlled trial. J Med Internet Res 2004 Jun 02;6(2):e16 [FREE Full text] [doi: $\underline{10.2196 / j m i r .6 .2 . e 16}$ ] [Medline: 15249265] 
65. Rusy LM, Weisman SJ. Complementary therapies for acute pediatric pain management. Pediatr Clin North Am 2000 Jun;47(3):589-599. [doi: 10.1016/s0031-3955(05)70227-3]

66. Smith CA, Levett KM, Collins CT, Armour M, Dahlen HG, Suganuma M. Relaxation techniques for pain management in labour. Cochrane Database Syst Rev 2018 Mar 28;3:CD009514 [FREE Full text] [doi: 10.1002/14651858.CD009514.pub2] [Medline: 29589650]

67. Pyati S, Gan TJ. Perioperative pain management. CNS Drugs 2007;21(3):185-211. [doi: 10.2165/00023210-200721030-00002] [Medline: 17338592]

68. Carroll D, Seers K. Relaxation for the relief of chronic pain: a systematic review. J Adv Nurs 1998 Mar 25;27(3):476-487. [doi: 10.1046/j.1365-2648.1998.00551.x] [Medline: 9543032]

69. Crouch R, Alers V. Occupational Therapy in Psychiatry and Mental Health. West Sussex, UK: Wiley Blackwell; 2014:978-971.

70. Robb SL. Music assisted progressive muscle relaxation, progressive muscle relaxation, music listening, and silence: a comparison of relaxation techniques. J Music Ther 2000 Mar 01;37(1):2-21. [doi: 10.1093/jmt/37.1.2] [Medline: 10806470]

71. Stark DP, House A. Anxiety in cancer patients. Br J Cancer 2000 Nov;83(10):1261-1267 [FREE Full text] [doi: 10.1054/bjoc.2000.1405] [Medline: 11044347]

72. Yohannes AM, Alexopoulos GS. Depression and anxiety in patients with COPD. Eur Respir Rev 2014 Sep 31;23(133):345-349 [FREE Full text] [doi: 10.1183/09059180.00007813] [Medline: 25176970]

73. Quirk ME, Letendre AJ, Ciottone RA, Lingley JF. Anxiety in patients undergoing MR imaging. Radiology 1989 Feb;170(2):6-463. [doi: 10.1148/radiology.170.2.2911670] [Medline: 2911670]

\title{
Abbreviations \\ PRISMA: Preferred Reporting Items for Systematic Reviews and Meta-analysis \\ VR: virtual reality
}

\author{
Edited by L Buis; submitted 25.11.20; peer-reviewed by S Chen, HJ Jeon, R Liu; comments to author 29.01.21; revised version received \\ 16.02.21; accepted 31.03.21; published 22.04.21 \\ Please cite as: \\ Alneyadi M, Drissi N, Almeqbaali M, Ouhbi S \\ Biofeedback-Based Connected Mental Health Interventions for Anxiety: Systematic Literature Review \\ JMIR Mhealth Uhealth 2021;9(4):e26038 \\ URL: https://mhealth.jmir.org/2021/4/e26038 \\ doi: $10.2196 / 26038$ \\ PMID: $\underline{3792548}$
}

CMahra Alneyadi, Nidal Drissi, Mariam Almeqbaali, Sofia Ouhbi. Originally published in JMIR mHealth and uHealth (https://mhealth.jmir.org), 22.04.2021. This is an open-access article distributed under the terms of the Creative Commons Attribution License (https://creativecommons.org/licenses/by/4.0/), which permits unrestricted use, distribution, and reproduction in any medium, provided the original work, first published in JMIR mHealth and uHealth, is properly cited. The complete bibliographic information, a link to the original publication on http://mhealth.jmir.org/, as well as this copyright and license information must be included. 